\title{
A investigação realizada no âmbito do Mestrado em Ciências da Educação, especialização em Supervisão Pedagógica na ESE de Paula Frassinetti
}

\author{
An analysis of research carried out under the Master in Educational Sciences in the ESEPF
}

\author{
Elvira Rodrigues*, Daniela Gonçalves** \\ *Doutoranda em Ciências da Educação na Universidade de Trás os Montes e Alto Douro (UTAD) **Docente da Escola Superior de \\ Educação de Paula Frassinetti (ESEPF)
}

\begin{abstract}
Resumo
Instituído pelo Despacho n 20758/2009 de 15 de setembro ( $2^{\mathrm{a}}$ série), o Mestrado em Ciências da Educação, especialização em Supervisão Pedagógica (MCESP) da Escola Superior de Educação de Paula Frassinetti (ESEPF) já vai na sua $5^{a}$ edição e emerge da conscencialização de que, no atual contexto da carreira docente, a supervisão pedagógica é a via privilegiada para o assumir de responsabilidades de coordenação, enquadramento e avaliação de equipas de professores e agentes educativos. Apresentamos os resultados da análise efetuada aos 37 trabalhos de projeto disponíveis no repositório online e respetivos domínios de investigação e orientações metodológicas destes trabalhos académicos.

Palavras-chave: Ciências da Educação; Supervisão Pedagógica; Investigação.
\end{abstract}

\begin{abstract}
Established by Order No. 20758/2009 of September 15 (2nd series), a Masters in Educational Sciences, specialization in Educational Supervision (MCESP) of the School of Education Paula Frassinetti (ESEPF) now in its 5th edition and emerges from the requirement that, in the current context of the teaching profession, the pedagogical supervision is assumed as the preferred route to take responsibility for coordination, supervision and evaluation of teachers and educators teams.

We present the results of the analysis carried out after 37 design jobs available in the repository online and the related fields of research and methodological orientations of these academic works .
\end{abstract}

Keywords : Educational Sciences; Supervision; Research .

\section{Introdução}

Uma rápida pesquisa na internet através do motor de busca Google, sob as premissas de "supervisão pedagógica”, "mudanças da escola e supervisão pedagógica” e "supervisão e colaboração", coloca-nos perante 489.000 resultados em 31 segundos, 295.000 resultados em 33 segundos e 468.000 resultados em 32 segundos, respetivamente. Quando passamos para uma seleção no Google Académico os resultados são de 32.100 resultados em 3 segundos para o primeiro caso e 26.400 resultados em 8 segundos para o segundo caso.
Se, numa terceira investida pela web wordld wide nos confinarmos ao Google Livros, a "supervisão pedagógica” apresenta 7050 resultados em 30 segundos e as "mudanças da escola e supervisão pedagógica”, 557 em 31 segundos (pesquisa efetuada a 31 de maio 2015, às 16 horas).

Estes números ilustram a crescente produção académica em torno desta temática, numa altura em que, cada vez mais, novos saberes e novas competências são exigidas aos professores, num convite à interação de profissionais e instituição, com vista a um olhar, (re)construído sobre a realidade, socorrendo-se da trilogia proposta por Dewey (1971): abertura de espírito, responsabilidade e entusiasmo. Com efeito, ao longo dos tempos, temos vindo a assistir a uma polissemia associada ao conceito de supervisão, que, de movimentos fragmentários, tem vindo a orientar-se para um campo de compreensão e atuação integrada.

Contudo, e não obstante esta proliferação de produção académica associada à supervisão pedagógica, não abundam ainda muitos estudos sobre as mutações que lhe estão imbricadas numa perspetiva de formação contínua e continuada, tal como nos é apresentada por Coimbra, Marques e Martins (2012:32). As mudanças sócio económicas, a (re)configuração profissional e os contínuos desafios que se colocam à escola, enquanto instituição, e aos professores enquanto profissionais, motivam a procura de formação especializada nesta área, como uma forma de tentar acompanhar as mudanças da(s) prática(s) e a pressão gerada pelos normativos em torno da avaliação de desempenho docente, que vão sendo publicados.

O Decreto Regulamentar 26/2012, de 21 de fevereiro, cimenta a importância da formação especializada em supervisão pedagógica e avaliação de desempenho, ao criar uma bolsa externa de avaliadores para docentes que solicitem aulas assistidas no processo avaliativo de desempenho docente.

Assiste-se, também, como referem Alarcão e Canha (2013), a alguma indefinição concetual do termo "supervisão", manifestada em conceitos conexos como: formação; coaching; gestão; administração; coordenação; liderança; mediação; monitorização; regulação; inspeção/fiscalização e avaliação.

*Professora da Escola Secundária Augusto Gomes; Formadora do CFAE-Matosinhos; colaboradora do Centro de Estudos de Desenvolvimento Humano da Universidade Católica do Porto; **Membro integrado do Centro de Estudos de Desenvolvimento Humano da Universidade Católica do Porto.

*elvirarodrigues@esag-edu.net; **daniela@esepf.pt

Selección y peer-review bajo responsabilidad del Grupo de Investigación G000422-GIPDAE, Universidade da Coruña, España. 
É nesta perspetiva de educação transformadora, de visão com sentido(s), assente numa escola reflexiva, numa dinâmica colaborativa de co construção do saber, em que nos inscrevemos

A supervisão como instrumento de autoregulação institucional e profissional revela-se cada vez mais, essencial. Supervisionar numa vertente colaborativa, em que o professor se assume como o ator e agente crítico da mudança, contributo para a democratização do processo de construção do conhecimento, promoção da comunicação dialógica através do cruzamento de experiências, interesses e expetativas. O desenho, realização e monitorização de planos de intervenção poderá constituir-se como um vasto campo de possibilidades no ensino e na aprendizagem, de que a desmultiplicação em contexto de bons exemplos, conjugados com o interesse, comunidade e práticas, estão na génese das COP (Comunidades de Práticas) e constituem um desafio cada vez mais emergente.

\section{Metodologia adotada}

A nossa base de dados é constituída por 37 trabalhos de projeto de mestrado em Ciências da Educação, área de especialização em Supervisão Pedagógica concluídas na ESEPF entre 2011 e 2014 distribuídas conforme consta da Tabela 1.

Tabela 1.

Distribuição dos trabalhos de projeto por ano

\begin{tabular}{ccccc}
\hline ANO & 2011 & 2012 & 2013 & 2014 \\
\hline $\begin{array}{l}\mathrm{N}^{\circ} \text { de } \\
\text { trabalhos de }\end{array}$ & 12 & 11 & 9 & 5 \\
Projeto & & & & \\
\hline
\end{tabular}

Fonte: Repositório ESEPF.

O objeto de análise deste estudo exploratório são os 37 trabalhos de projetos de mestrado. Numa primeira etapa começamos por elencar a informação emergente da sua leitura em 5 itens, a saber: ano de conclusão; título; pergunta de partida/objetivos norteadores; opções metodológicas e instrumentos de recolha de dados. Dessa análise preliminar, resultou uma primeira abordagem enquanto contributo inicial para o nosso propósito - a elaboração de um roteiro temático.

Seguiu-se uma análise de conteúdo exaustiva, realizada individualmente pelas duas autoras deste artigo. Numa fase posterior, confrontamos os dados obtidos através dessa análise. Verificaram-se muito poucos casos de discordância, mas os existentes foram resolvidos, através de uma análise conjunta, consubstanciada com recurso a outras secções dos trabalhos consultados.

\section{Apresentação e discussão de resultados}

Uma das primeiras conclusões a retirar da leitura e análise de conteúdo realizadas, foi a coesão entre o título dos 37 Trabalhos de Projeto e os temas que se encontram desenvolvidos ao longo dos seus textos. Contudo, quando passamos à análise de conteúdo do "resumo", este nem sempre se revela muito esclarecedor sobre os propósitos teóricos e metodológicos que consubstanciam e enformam estes trabalhos académicos.

Tendo em consideração a importância de procurar enunciar o projeto de investigação na forma de uma pergunta de partida e/ou norteadora, e partindo do pressuposto de que esta é esclarecedora quanto à finalidade e propósito do trabalho a realizar, procuramos identificá-la e, quando esta não existe, ou se revela pouco clara, centramo-nos nos objetivos norteadores dos trabalhos de investigação que integram a nossa base de dados.

\section{Temáticas abordadas}

Consideramos as 10 categorias que emergiram da análise efetuada (categorias aposteriori) e que constam da tabela 2 conjugadas com os 37 indicadores que a leitura destes trabalhos académicos permitiram, igualmente, determinar aposteriori (Quadro1).

Tabela 2.

Categorias temáticas dos Trabalhos de Projeto em análise

\begin{tabular}{l|c}
\multicolumn{1}{c|}{ Categorias Temáticas } & $\begin{array}{c}\mathrm{N}^{0} \text { de Trabalhos de } \\
\text { Projeto }\end{array}$ \\
\hline $\begin{array}{l}\text { Avaliação de Desempenho } \\
\text { Docente (ADD) }\end{array}$ & 4 \\
\hline $\begin{array}{l}\text { Docência e Supervisão } \\
\text { Pedagógica }\end{array}$ & 9 \\
\hline Educação de Adultos & 1 \\
\hline Educação Especial & 3 \\
\hline Formação Docente & 1 \\
\hline Inteligência Emocional & 5 \\
\hline Liderança Estratégica & 5 \\
\hline Lideranças Intermédias & 4 \\
\hline Práticas Avaliativas & 4 \\
\hline Tecnologias Educativas (TE) &
\end{tabular}

Fonte: Análise de conteúdo do resumo dos trabalhos de Projeto.

Quadro1.

Categorias temáticas e Indicadores dos Trabalhos de Projeto em análise

\begin{tabular}{|c|c|}
\hline $\begin{array}{l}\text { Categorias } \\
\text { Temáticas }\end{array}$ & Indicadores \\
\hline $\begin{array}{c}\text { A. } \\
\text { Avaliação de } \\
\text { Desempenho } \\
\text { Docente (ADD) }\end{array}$ & $\begin{array}{l}\text { A.1.*ADD na RAM } \\
\text { A.2.*Gestão do Desempenho } \\
\text { A.3.*Relação Interpessoal } \\
\text { Relator/Avaliado } \\
\text { A.4.*Todos os Educadores podem } \\
\text { ser Supervisores }\end{array}$ \\
\hline $\begin{array}{c}\text { B. } \\
\text { Docência e } \\
\text { Supervisão } \\
\text { Pedagógica }\end{array}$ & $\begin{array}{l}\text { B.1. Percecões sobre a Supervisão } \\
\text { pedagógica } \\
\text { B.2.*Contributos da Supervisão } \\
\text { Pedagógica na Organização da Expressão e } \\
\text { Educação Físico-Motora no } 1^{\circ} \text { Ciclo } \\
\text { B.3.*Gabinete de Ação Tutorial } \\
\text { B.4.*Interação na supervisão da prática } \\
\text { pedagógica em contexto de estágio }\end{array}$ \\
\hline
\end{tabular}


B.5.*Leitura e Escrita na Educação PréEscolar

B.6. Mal estar docente-proposta intervenção;

B.7.*Operacionalização do programa de Matemática no $1^{\circ}$ Ciclo (RAM)

B.8.*Referencial de Competências

Transversais (pré-escolar; $1^{\circ}$ e $2^{\circ}$ Ciclo)

B.9.*Trabalho Colegial em contexto de Creche

\begin{tabular}{|c|c|}
\hline $\begin{array}{c}\text { C. } \\
\text { Educação de } \\
\text { Adultos } \\
\end{array}$ & C.1.*Prática Pedagógica \\
\hline $\begin{array}{l}\text { D. } \\
\text { Educação } \\
\text { Especial }\end{array}$ & $\begin{array}{l}\text { D.1.*Fobia Escolar } \\
\text { D.2.*Perspetivas e Práticas dos professores } \\
\text { do ensino regular e educação especial } \\
\text { D.3.*Supervisão Pedagógica colaborativa }\end{array}$ \\
\hline \begin{tabular}{l}
\multicolumn{1}{c}{ E. } \\
Formação \\
Docente \\
\end{tabular} & E.1.*Formação de Educadores de Infância \\
\hline $\begin{array}{c}\text { F. } \\
\text { Inteligência } \\
\text { Emocional }\end{array}$ & $\begin{array}{l}\text { F.1.*Crescimento Emocional e Supervisão } \\
\text { Pedagógica }\end{array}$ \\
\hline $\begin{array}{c}\text { G. } \\
\text { Liderança } \\
\text { Estratégica }\end{array}$ & $\begin{array}{l}\text { G.1.*Cultura Reflexiva e Colaborativa } \\
\text { G.2.*Conselho de Comunidade Educativa } \\
\text { (RAM) } \\
\text { G.3.*Olhar supervisivo sobre a Liderança } \\
\text { Escolar (RAM) } \\
\text { G.4.* Papel dos diretores do } 1^{\circ} \text { Ciclo } \\
\text { (RAM) } \\
\text { G.5.*Perfil de Liderança para o Século XXI }\end{array}$ \\
\hline $\begin{array}{c}\mathrm{H} . \\
\text { Lideranças } \\
\text { Intermédias }\end{array}$ & $\begin{array}{l}\text { H.1.*Desenvolvimento Profissional } \\
\text { H.2.*Perfil de Competências do } \\
\text { Supervisor da Educação Pré-Escolar } \\
\text { H.3.*Perfil do Supervisor do } 1^{\circ} \text { Ciclo do } \\
\text { Ensino Básico } \\
\text { H.4.*Perfil do diretor do Curso } \\
\text { Profissional H.5Supervisor Pedagógico na } \\
\text { Educação Pré-Escolar } \\
\text { H.6.*Supervisão Pedagógica Interpares }\end{array}$ \\
\hline $\begin{array}{c}\text { I. } \\
\text { Práticas } \\
\text { Avaliativas }\end{array}$ & $\begin{array}{l}\text { I.1.*Avaliação de Aprendizagens } \\
\text { I.2.*Autoavaliação de escolas } \\
\text { I.3.*Avaliação em contexto de jardim de } \\
\text { infância } \\
\text { I.4.*Avaliação formativa - estratégias no } 1^{\circ} \\
\text { Ciclo }\end{array}$ \\
\hline $\begin{array}{c}\text { J. } \\
\text { Tecnologias } \\
\text { Educativas } \\
\text { (TE) }\end{array}$ & $\begin{array}{l}\text { J.1.* Ferramenta Online - Grelhas de } \\
\text { Avaliação para o } 1^{\circ} \text { Ciclo do Ensino } \\
\text { Básico J.2.*Utilização das Ferramentas } \\
\text { Web } 2.0 \text { em contexto educativo } \\
\text { J.3.*Utilização da Plataforma Escola } \\
\text { Virtual } \\
\text { J.4.*Novos Saberes e Novas Competências } \\
\text { na Docência }\end{array}$ \\
\hline
\end{tabular}

Fonte: Análise de conteúdo do resumo dos Trabalhos de Projeto.

As categorias "Docência e Supervisão Pedagógica”, "Liderança Estratégica” e "Lideranças Intermédias" adquirem uma clara primazia sobre as demais com uma percentagem de $24,3 \%$ e $13,5 \%$ para cada uma das categorias relativas a liderança, respetivamente.

As pressões exercidas pelas alterações ao Estatuto da Carreira Docente de janeiro de 2007 ( $8^{\mathrm{a}}$ alteração) e pela avaliação de desempenho docente consignada pelo Decreto Regulamentar n. ${ }^{\circ}$ 2/2008, de 10 de janeiro, génese, por um lado, de reações de revolta e resistência e, por outro, de motivação e (re)investimento na formação especializada de professores, consubstanciada no Estatuto da Carreira Docente, no $\operatorname{art}^{\circ} 42$, alínea a) e no Diário da República, $1 .^{\mathrm{a}}{ }^{\text {série, }}$ n. $^{\circ} 126,2$ de julho de 2012, ponto 5 do artigo 43, podem assumir-se como uma explicação possível para a crescente procura de formação académica ligada à supervisão pedagógica conjugando as dimensões pessoais, profissionais e organizacionais, com o significativo aumento da oferta e procura de especializações, mestrados e pós graduações em torno desta temática, da avaliação de desempenho docente e, ainda, de novas dinâmicas organizacionais, com especial incidência para a liderança de topo e lideranças intermédias as quais assumem um importante papel enquanto responsáveis pela implementação e otimização de dinâmicas supervisivas. Uma liderança forte, conjuntamente com novos paradigmas de escola e sala de aula, adequação de «mecânicas de proximidade» por perfil dos alunos, inovação nos processos e rotinas e ligação escola-empresa, é apontada como um dos cinco pilares das escolas de futuro (Manual do Projeto Épis, 2009). Assim se compreende o destaque que é dado às hard skills - pensamento estratégico, planeamento, accountability e prestação de contas, gestão de projetos e inovação e às soft skills - gestão e motivação de equipas, influência positiva, gestão de conflitos, comunicação interna e externa, angariação e gestão de parcerias.

A prevalência de estudos ao nível da educação pré-escolar, $1^{\circ}$ e $2^{\circ}$ ciclos, surge naturalmente, uma vez que uma parte significativa dos estudantes de mestrado que, numa primeira fase, procura esta instituição são ex-diplomados, ou seja, emergem dos cursos de $1^{\circ}$ ciclo lecionados na ESEPF. Um curso de especialização em Supervisão Pedagógica lecionado na Região Autónoma da Madeira (RAM), no ano de 2012, a cujos estudantes foi dada a oportunidade de continuarem para o curso de mestrado no Continente, explica um conjunto de trabalhos de projeto cuja investigação se centrou na RAM. Por outro lado, o sucesso das três primeiras edições deste curso, com as necessários reflexos no contexto de algumas instituições de origem dos mestrandos, traduz-se num significativo aumento de mestrandos a lecionar no $3^{\circ}$ ciclo e ensino secundário, o que explica um conjunto de novos estudos e temas voltados para estas duas realidades. Por sua vez, a "Educação de Adultos" e "Formação Docente" apenas são objeto de abordagem em dois Trabalhos de Projeto. No primeiro caso, o espaço cronológico em análise coincide com a saída de novos normativos para a educação de adultos que transformam os Centros de Novas Oportunidades (CNO) em Centros para a Qualificação e o Ensino Profissional (CQEP). No segundo caso, se é verdade que apenas um trabalho de projeto se debruça objetivamente sobre questões de formação docente, uma leitura cuidada rapidamente nos colocou perante vários trabalhos que, embora tendo como tema central outras questões, têm na formação 
elementos de análise e recolha de dados ou formas de solução e atuação em contexto. As questões em torno da avaliação de desempenho docente (ADD) estavam na "ordem do dia” em 2011, o que explica a sua escolha para a realização de um trabalho de projeto académico. Assim, e embora, sejam apenas se contabilizem 4 trabalhos, a sua leitura coloca-nos perante um leque muito abrangente de abordagens, as quais, para além de questionarem o perfil dos avaliadores no âmbito de uma supervisão interpares, abordam ainda as relações interpessoais na relação avaliador/avaliado; questões de gestão do desempenho e, no caso da RAM, estamos perante um estudo muito abrangente e que lança perspetivas e conclusões sobre a realidade específica desta ilha, no que à avaliação de desempenho docente diz respeito.

Nas dicotomias que [ainda] se colocam à escola, as questões da avaliação de desempenho docente continuam na ordem do dia. Contudo, e embora conscientes da importância de um processo reflexivo crítico, continua a faltar, em muitos casos, a vertente formativa, enquanto processo de gestão de melhoria, capaz de conduzir e operacionalizar mudança(s). Uma gestão de desempenho docente assente numa lógica supervisiva de desenvolvimento, assumindo uma postura sistémica e de reconhecimento, que contrarie uma postura de controlo e desprezo, revela-se, assim, fundamental.

As práticas avaliativas, para além de aspetos específicos ligados à avaliação das aprendizagens, centra-se ainda, através de um estudo de caso, na questão da autoavaliação de escolas.

As novas técnicas e metodologias de aprendizagem e de formação, de que o e-learning e o b-learning são exemplo, associadas à partilha em comunidades de prática, são apenas alguns dos desafios que se colocam aos professores nesta segunda década do século XXI, em que as tecnologias educativas no e par o ato de ensino marcam presença, como as quatro em torno da temática aglutinadora “Tecnologias Educativas” evidencia desde a criação de novas ferramentas; utilização das já existentes ou uma perspetiva mais abrangente em torno dos novos saberes e novas competências para a docência neste século XXI.

É numa perspetiva de educação transformadora, de visão com sentido(s), assente numa escola reflexiva, numa dinâmica colaborativa de co construção do saber, que estes 37 trabalhos académicos repartidos por uma dezena de categorias se inserem.

A mudança, numa ótica de transformação e não de adaptação, assume um papel primordial, onde a implicação (envolvência) deve estar presente. A supervisão é uma procura, uma busca de mais e melhor, numa lógica colaborativa, atentos ao facto de ser, ou não, o momento para a transformação.

À escola, nesta segunda década do século XXI, colocam-se essencialmente três grandes desafios: ser capaz de conjugar a racionalidade económica com uma regulação que se pretende crítica e democratizante e que associe a(s) (re)construção(ões) da profissionalidade docente com a (re)organização da escola; criar a capacidade de mudança na própria escola e fazer com que essa mudança seja sustentável, ou seja, a capacidade de a escola continuar a adaptar-se e a encarar a melhoria face a novos desafios e a novos contextos - school's capacity for managing change - (Bolívar, 2012:22).

\section{Análise das Opções Metodológicas}

A análise das opções metodológicas, em sentido amplo, no que ao paradigma de investigação diz respeito, permitiu identificar 3 categorias (tabela 3).

Tabela 3.

Opções metodológicas dos Trabalhos de Projeto em análise

\begin{tabular}{l|l}
\multicolumn{1}{c|}{ Opções Metodológicas } & \multicolumn{1}{c}{$\mathrm{N}^{\mathrm{o}}$ de Teses } \\
\hline Qualitativa & 28 \\
\hline Quantitativa & 6 \\
\hline Mista & 3 \\
\hline Total & 37
\end{tabular}

Fonte: Repositório online da ESEPF.

Destacam-se os projetos que recorrem a um paradigma metodológico qualitativo, em que, na triangulação de dados, conjugam várias fontes e instrumentos de recolha de dados (inquérito por entrevista; análise documental; observação participante; focus group; grupos de discussão...).Contudo, apenas em três se percebe claramente estarmos perante uma metodologia mista e somente em seis se assume, ou se depreende pela sua leitura, estarmos claramente perante uma metodologia quantitativa assente essencialmente em inquéritos por questionário. A conjugação destas opções com as temáticas constantes dos diferentes trabalhos permite-nos também concluir que a metodologia qualitativa é, não só, a mais adequada a estes estudos, como aquela que melhor se ajusta aos timings, sempre curtos para a conclusão dos mesmos dentro dos prazos estipulados.

\section{Considerações Finais}

Na realização deste estudo exploratório recorremos a uma análise de conteúdo emergente da leitura das Trabalhos de Projeto do mestrado em Ciências da Educação, especialização em Supervisão Pedagógica, que se encontram no repositório online da ESEPF. Assim, e como mencionamos, numa primeira etapa procedemos a uma sistematização inicial estruturada a partir de 5 itens: ano de conclusão; título e palavras chave; questão de partida/objetivos norteadores; metodologia; instrumentos de recolha de dados e domínio de investigação. Seguiu-se uma análise de conteúdo bastante exaustiva, a qual permitiu chegar a um consenso e individualizar 10 categorias temáticas e 37 indicadores, dos quais se destacam, como já mencionamos, 3 categorias, a saber: docência e supervisão pedagógica; liderança estratégica e lideranças intermédias.

A diminuição do número de Trabalhos de Projeto em 2014 pode explicar-se pelas crescentes dificuldades em conciliar a atividade docente e um avolumar de exigências, nomeadamente burocráticas, com a 
realização de uma investigação de mestrado, cumprindo os prazos estipulados, obrigando, na generalidade dos casos, a um pedido de prorrogação.

Da leitura efetuada ressalta o interesse em traçar o perfil dos mestrandos nesta área, nomeadamente no que à idade e percurso profissional diz respeito. Deste modo, muito interessante selecionar uma percentagem de estudantes de $2^{\circ}$ ciclo em Ciências da Educação, especialização em Supervisão Pedagógica e acompanhar o seu percurso nos dois ou três anos subsequentes (aplicação das suas propostas no terreno; continuação dos trabalhos de investigação;(des)construções profissionais, entre outros).

Tal como propõem Coutinho e Gomes (2005:11), também nós gostaríamos de continuar este estudo e proceder à aplicação de inquéritos por questionário e inquéritos por entrevista a autores e orientadores de alguns destes Trabalhos de projeto já concluídas.

\section{Referências}

ALARCÃO, Isabel, CANHA, Bernardo (2013). Supervisão e Colaboração. Uma Relação para o Desenvolvimento. Porto: Porto Editora.
BOLÍVAR, António (2012). Melhorar os Processos e os Resultados Educativos, o que nos Ensina a Investigação. Porto: Fundação Manuel Leão.

COUTINHO; Clara, GOMES, Maria (2005) Uma Análise da investigação realizada no âmbito do Mestrado em Tecnologia Educativa da Universidade do Minho. In Actas do XIV Colóquio da AFIRSE. Para um Balanço da Investigação em Educação de 1960 a 2005. Teorias e Práticas. Consultado em [maio 2015] em http://repositorium.sdum.uminho.pt/handle/1822/76 61.

DEWEY, John (1973). Experiência e Educação. São Paulo: Companhia Ed. Nacional.

\section{Legislação Consultada}

Estatuto da Carreira Docente

Disponível em http://legislacao.min-edu.pt/np4/140, consulta efetuada a 31 de maio de 2015, às 14 horas.

Decreto Regulamentar n. ${ }^{\circ}$ 2/2008, de 10 de janeiro.

Decreto-Lei $n^{\circ} 75 / 2010$, de 23 de junho.

Decreto Regulamentar 26/2012, de 21 de fevereiro.

Diário da República, $1 .^{\mathrm{a}}$ série, N. ${ }^{\circ} 126,2$ de julho de 2012.

\section{Observação:}

Observação: Este artigo apenas integra os Trabalhos de Projeto de Mestrado em Ciências da Educação da área de especialização em Supervisão Pedagógica a que as autoras tiveram acesso através do repositório online da ESEPF. 